\author{
ARTIGO \\ dol https://doi.org/10.22481/rpe.v16i43.6508
}

\title{
O PIBID COMO ESPAÇO COLABORATIVO NA FORMAÇÃO INICIAL DE PROFESSORES QUE ENSINAM MATEMÁTICA
}

\author{
PIBID AS A COLLABORATIVE SPACE IN THE INITIAL TRAINING OF TEACHERS \\ WHO TEACH MATHEMATICS
}

\begin{abstract}
PIBID COMO ESPACIO COLABORATIVO EN LA FORMACIÓN INICIAL DE PROFESORES QUE ENSEÑAN MATEMÁTICAS
\end{abstract}

\author{
Klinger Teodoro Ciríaco \\ Universidade Federal de São Carlos - Brasil \\ Yandra Karla dos Santos \\ Universidade Federal de Mato Grosso do Sul - Brasil
}

\begin{abstract}
Resumo: $\mathrm{O}$ artigo relata resultados de uma investigação com o objetivo de compreender como a prática colaborativa de estudos, reflexões e intervenções de um grupo de iniciação à docência constitui-se espaço de aprendizagem compartilhada "de" e "sobre" a docência em Matemática. Para isso, adota-se um referencial teórico que trata da formação inicial de professores e práticas de colaboração. A metodologia se inscreve no campo dos estudos qualitativos em educação, de caráter descritivo analítico, em que os dados foram produzidos com base em entrevistas semiestruturadas com duas integrantes do Programa Institucional de Bolsas de Iniciação à Docência (PIBID), uma egressa e outra bolsista. Da análise de dados, foi possível retratar que o programa constituiu-se, desde sua implementação em 2014 na Universidade com a qual trabalhamos, espaço de aprendizagem de futuros professores pautado em dinâmicas colaborativas, o que contribuiu, sobremaneira, para a superação das dificuldades em Matemática, bem como para a formação dos envolvidos no que tange aos aspectos do conhecimento didático para o ensino e do conhecimento matemático para a abordagem de determinados conteúdos em sala de aula. Além disso, a inserção no PIBID resultou em uma mudança de postura frente a disciplina e ainda oportunizou, para as colaboradoras, uma identidade com a pesquisa neste campo.
\end{abstract}

Palavras chave: Formação Inicial; Programa de Iniciação à Docência; Colaboração; Ensino de Matemática.

Abstract: The article reports results of an investigation with the objective of understanding how the collaborative practice of studies, reflections and interventions of a group of initiation to teaching is constituted as a shared learning space "of" and "about" teaching in Mathematics. For this, a theoretical framework is adopted that deals with initial teacher training and collaborative practices. The methodology is part of the field of qualitative studies in education, of an analytical descriptive character, in which the data were produced based on semi-structured interviews with two members of the Institutional Program for Teaching Initiation Scholarships (PIBID), one graduate and one fellow. From the data analysis, it was possible to portray that the program has constituted, since its implementation in 
2014 at the University with which we work, a space for the learning of future teachers based on collaborative dynamics, which contributed greatly to overcoming the difficulties in Mathematics, as well as for the training of those involved with regard to aspects of didactic knowledge for teaching and mathematical knowledge to approach certain content in the classroom. In addition, inclusion in PIBID resulted in a change in attitude towards the discipline and also provided the collaborators with an identity with research in this field.

Keywords: Initial formation; Teaching Initiation Program; Collaboration; Mathematics teaching.

Resumen: El artículo reporta los resultados de una investigación con el objetivo de comprender cómo la práctica colaborativa de estudios, reflexiones e intervenciones de un grupo de iniciación a la docencia se constituye como un espacio de aprendizaje compartido "de" y "sobre" la enseñanza en Matemáticas. Para ello, se adopta un marco teórico que aborda la formación inicial del profesorado y las prácticas colaborativas. La metodología se enmarca en el campo de los estudios cualitativos en educación, de carácter analítico descriptivo, en el cual los datos fueron producidos a partir de entrevistas semiestructuradas con dos integrantes del Programa Institucional de Becas de Iniciación Docente (PIBID), un egresado y un becario. A partir del análisis de los datos se pudo retratar que el programa ha constituido, desde su implementación en 2014 en la Universidad con la que trabajamos, un espacio para el aprendizaje de los futuros docentes basado en dinámicas colaborativas, lo que contribuyó en gran medida a superar las dificultades en Matemáticas, así como para la formación de los implicados en aspectos del conocimiento didáctico para la enseñanza y el conocimiento matemático para abordar determinados contenidos en el aula. Además, la inclusión en PIBID resultó en un cambio de actitud hacia la disciplina y también brindó a los colaboradores una identidad con la investigación en este campo.

Palabras clave: Formación inicial; Programa de iniciación docente; Colaboración; Enseñanza de matemática.

\section{Introdução}

Este artigo tem como objetivo compreender como a prática colaborativa de estudos, reflexões e intervenções de um grupo de iniciação à docência constitui-se espaço de aprendizagem compartilhada "de" e "sobre" a docência em Matemática. Os dados foram produzidos no contexto do PIBID da licenciatura em Pedagogia da Universidade Federal de Mato Grosso do Sul - UFMS, Campus Naviraí, com base na descrição detalhada da vivência de duas futuras professoras neste ambiente formativo, como também de entrevistas semiestruturadas concedidas pelas mesmas.

O tema gerador deste trabalho surgiu de nossa participação no programa de iniciação à docência, desde março de 2014. Neste espaço/tempo, ao atuar e observar a metodologia adotada para a dinâmica e direcionamento das ações coletivas entre seus partícipes, percebemos que os acadêmicos apresentavam um preparo diferenciado para encarar a jornada tanto acadêmica (em demais disciplinas na Universidade) quanto prática (em termos de desempenho didático em sala de aula). Mesmo que sem "cientificizar" o processo, apenas num primeiro 
momento enquanto espectadores passivos, notamos ainda que para algumas bolsistas egressas a transição para a vida docente parecia, ao que a observação indicava, ser mais pacífica, menos traumática, uma vez que estas, no contexto do PIBID, enfrentavam situações diversas do cotidiano escolar.

Assim, amparados na experiência, buscamos responder: Como a prática de colaboração, em um programa de iniciação à docência, constitui-se espaço do aprender a ensinar Matemática?

Um estudo detalhado das possíveis contribuições deste programa, especificamente sobre a Educação Matemática nos anos iniciais em uma interlocução com as experiências formativas de suas integrantes, pode trazer elementos importantes para a relação teoria e prática, aproximação com a escola, conhecimento da dinâmica do trabalho docente e da rotina de classes de alfabetização matemática para o futuro docente, razão pela qual defendemos ser este espaço um lugar de colaboração e, portanto, de aprendizagens compartilhadas dos saberes necessários à docência.

$\mathrm{Na}$ perspectiva da defesa em questão, o artigo estrutura-se em: a) aspectos introdutórios, onde demarcamos as justificativas e escolhas da pesquisa; b) referencial teórico, subdividido em duas seções (práticas de colaboração e levantamento de pesquisas sobre o PIBID no campo da Educação Matemática); c) abordagem metodológica; d) descrição e análise de dados, que tenta dialogar com as vozes das entrevistadas e; e) considerações finais acerca do trabalho no sentido de tecer limites e perspectivas futuras.

\section{Questões introdutórias sobre a colaboração na formação de professores que ensinam Matemática $^{1}$}

No Brasil, há algum tempo, inúmeros trabalhos de pesquisas vêm apontando problemas da formação docente, tanto em linhas gerais, quanto sobre características mais específicas decorrentes da especificidade de cada licenciatura (PIMENTA, 1996; DINIZPEREIRA, 2006; GHEIDIN, ALMEIDA, LEITE, 2008). Em certa medida, tais estudos entram num consenso que o distanciamento da prática pedagógica é, sem dúvida, a questão central a ser resolvida se quisermos garantir uma formação de professores mais situada,

\footnotetext{
${ }^{1}$ Neste trabalho, referimo-nos "professores que ensinam Matemática" àqueles com formação inicial em Pedagogia, uma vez que dada especificidade de sua formação (polivalência) a Matemática não é objeto específico do curso de licenciatura do qual são egressos, mas constitui-se campo de ensino. Portanto, o pedagogo é um "professor que ensina Matemática" e não um "professor de Matemática".
} 
consistente e que, de fato, contribua para a construção da identidade do profissional da educação.

Fusari (1988), afirma que conhecer o cotidiano escolar e a realidade vivida na escola são instâncias privilegiadas para a formação do educador. Com isso, acreditamos ser preciso um movimento de aproximação com as práticas escolares, desde o curso de licenciatura, momentos estes em que por meio de atividades de ensino, pesquisa e extensão universitária, o futuro professor pode "tatear" o lugar que o espera após sua colação de grau, em decorrência da inserção no mundo do trabalho.

Em relação à formação para o ensino de Matemática, em cursos de Pedagogia, autores como Gomes (2002), Curi (2004) e Ciríaco (2016) destacam ser preciso repensar o caminho com o qual os conteúdos matemáticos se apresentam nesta licenciatura, pois é certo, em concordância com a literatura da temática, que os programas e ementas das disciplinas de fundamentos e metodologias destinadas à área trabalham mais processos metodológicos quando comparados com o conteúdo específico da matéria de ensino.

De modo comum, o distanciamento de futuros professores da Educação Matemática torna-se cada vez mais presente em resultados de investigações. Curi (2004), em um estudo sobre conhecimentos para se ensinar Matemática na formação do pedagogo, afirma que existe uma fragmentação exacerbada do conteúdo matemático nas experiências que este participa em sua formação inicial, o que reflete na crença de que para se ensinar basta compreender o "como", conhecer as estratégias e recursos, deixando a abordagem conceitual em desvantagem.

Em concordância com a autora, Ciríaco e Morelatti (2016, p. 271) advogam:

Os futuros professores aprendem muitas estratégias de ensino, conhecem algumas tendências curriculares, relacionadas a cada uma das matérias que terão de ensinar e as formas de aprendizagem das crianças, mas o conhecimento específico do conteúdo quase sempre é deixado para segundo plano pela falta de tempo. Muitas vezes, esses professores em formação, no caso da disciplina de Matemática, licenciam-se sem conhecer, por exemplo, conteúdos de números racionais, números primos, expressões numéricas, geometria, grandezas e medidas, entre outros.

Face à tal realidade, ingressam na profissão e seguem com sérios problemas conceituais na constituição de suas práticas profissionais, o que pode implicar diretamente no processo de ensino e aprendizagem de seus alunos. Por essa razão, defendemos o posicionamento de que ao se implementar práticas de colaboração com futuros professores e professores em exercício, as situações em sala de aula podem ser melhor gerenciadas na perspectiva de resolver questões e dificuldades que possam surgir na relação entre a teoria e 
ação educativa. Daí surge a colaboração e a necessidade da formação de grupos colaborativos seja na Universidade ou na escola, espaço em que coletivamente todos podem se empreender para se desenvolverem profissionalmente.

A adesão deste tipo de proposta implica mudanças de concepções sobre o que seja aprender e ensinar Matemática em contextos diversificados, em diferentes níveis de ensino, uma vez que em ambientes de trabalho colaborativo encontram-se profissionais de fases distintas da carreira e com perspectivas/objetivos que podem se diferirem entre si. O anúncio da relevância da formação de redes de colaboração reside no fato de que, conforme menciona Freire (1987, p. 67): "Não há um saber mais, nem saber menos, há saberes diferentes".

Boavida e Ponte (2002), ao discutirem potencialidades e problemas da colaboração, destacam que este termo pode ser entendido como um meio que os sujeitos encontram para se alcançar um objetivo, porém, para os autores, o simples fato de trabalharem em conjunto não caracteriza um trabalho colaborativo, para isto é necessário vários fatores como, por exemplo, a confiança, o diálogo e a negociação nas tomadas de decisões.

Em seus estudos, Boavida e Ponte (2002) trazem um significado epistemológico/semântico para a palavra "colaboração" e a distingue do termo "cooperação". Os autores enfatizam que no caso da primeira (colaboração) temos uma articulação com o "laborare (trabalhar)" e a segunda com "operare (operar)" "[...] que, juntamente com o prefixo co, entram na constituição das palavras colaborar e cooperar" (BOAVIDA; PONTE, 2002, p. 4). Dito isso, podemos inferir que há uma diferença entre o trabalhar e operar, mas também, que ao integramos estas com o prefixo "co" as tornam ao mesmo tempo conceitos distintos e indissociáveis no começo de um trabalho que se quer colaborativo, ou seja, um grupo nasce cooperativo e torna-se colaborativo. Ambas compreendem movimento/interação/discussão, só que em intensidades e compromissos dosáveis pela experiência que se adquire com o tempo, com a vivência em/de um processo contínuo na busca pelo desenvolvimento de práticas para além do "trabalhar" junto. Boavida e Ponte (2002, p. 4), consideram ainda que:

[...] embora na vida corrente estas palavras sejam frequentemente usadas como sinónimos, o que não é de estranhar uma vez que ambas têm o prefixo co que significa acção conjunta, há uma diferença de alcance entre trabalhar e operar. Operar é realizar uma operação, em muitos casos relativamente simples e bem definida; é produzir determinado efeito; funcionar ou fazer funcionar de acordo com um plano ou sistema. Trabalhar é desenvolver actividade para atingir determinados fins; é pensar, preparar, reflectir, formar, empenhar-se. O plano do trabalho pode não estar completamente determinado antes do início do trabalho, da laboração. 
Diante dessas afirmações, necessitamos, então, compreender o que de fato pode ser considerado colaboração. Por mais semelhante que seja cooperar e colaborar, estas ações assumem posições de atuação que anunciam caminhos e perspectivas de trabalho diferentes. Podemos analisar o termo "cooperação" como um processo onde um determinado grupo realiza algumas atividades com um fim conjuntamente. Colaborar implica necessidade de que todos os membros assumam e compartilhem as responsabilidades (HARGREAVES, 1998).

Em vários campos de leitura são apresentados dois tipos de trabalho colaborativo: o forçado e o espontâneo (HARGREAVES, 1998). O trabalho forçado é apresentado como aquele que contém um supervisor, uma pessoa que tem a responsabilidade e institui/estipula práticas grupais de forma burocratizada como, por exemplo, reuniões escolares, horas de trabalho pedagógico e formações das secretarias impostas por órgãos superiores e que professores participam por ser uma atividade laboral. A colaboração espontânea é um tipo de trabalho que se desenvolve através da corresponsabilidade, momento em que todos são capazes de estarem prontos para tomadas de decisões conjuntas, beneficiando o fazer e a prática coletiva que é movido pelos interesses pessoais e, ao mesmo tempo, grupais de seus integrantes.

Em defesa da necessidade de implementação da colaboração espontânea em culturas docentes, é preciso acrescentar que o "[...] trabalho colaborativo possibilita o resgate de valores com o compartilhamento e a solidariedade que se foram ao longo do caminho trilhado por nossa sociedade, extremamente competitiva e individualista" (DAMIANI, 2008, p. 225). Para Alarcão e Canha (2013, p. 48):

Colaboração exige vontade de realizar com os outros. Implica, pois, confiança no outro, valorização dos seus saberes e experiências, acreditar que com ele é possível ir mais longe do que sozinho. E implica também humildade na valorização que fazemos do nosso próprio conhecimento e da nossa experiência, admitindo e desejando que eles se modifiquem e enriqueçam pelo encontro colaborativo.

Para diversos autores, a colaboração envolve um grau expressivo de comprometimento dos intervenientes voluntários no desenvolvimento profissional dos professores. No Brasil, Fiorentini (2004) se dedica aos estudos sobre os trabalhos colaborativos, sendo este autor um dos precursores deste tipo de prática ao defender a necessidade de se estudar problemas da prática escolar, especialmente em Educação Matemática, firmando parcerias entre a Universidade e a Educação Básica ao dar voz e vez aos professores em experiências de formação de grupos de estudos, como é o caso do Grupo de Sábado (GdS) ${ }^{2}$.

${ }^{2}$ O GdS é um subgrupo do PRAPEM-CEMPEM (Prática Pedagógica em Matemática - Círculo de Estudo Memória e Pesquisa em Educação Matemática) da FE/Unicamp que se reúne quinzenalmente, aos sábados pela 
Acreditamos, em com concordância com o autor, que criação/constituição de grupos colaborativos apresenta-se, na formação de professores que ensinam Matemática, como um possível caminho à superação e/ou minimização das dificuldades dos futuros professores. Para Fiorentini (2004), um grupo colaborativo se constitui, principalmente, por membros que participam voluntariamente, em um ambiente que possua liderança, mas que a responsabilidade compartilhada seja o alvo central, que o apoio e respeito mútuo venham se constituir para o avanço e o crescimento de todos os envolvidos tanto professores e acadêmicos quanto professores universitários.

Saraiva e Ponte (2003), ao discutirem o desenvolvimento profissional em Matemática por meio trabalho colaborativo, consideram que a colaboração contribui para sanar a fragmentação que se constitui entre a teoria e a prática, bem como para aproximação do professor com a investigação educacional, o que contribui consequentemente para parceria entre Universidade-Escola. Ainda para os autores:

$\mathrm{O}$ professor não funciona aqui como um mero utilizador do produto da investigação. Ele apresenta ao investigador as formas de pensamento que traz para a prática e a investigação é, para ele, uma ajuda para a sua própria reflexão-na-ação. [...] este tipo de investigação exige uma parceria entre o professor e investigador e pode tomar várias formas, sendo uma delas a constituição de grupos colaborativos (SARAIVA; PONTE, 2003, p. 9).

Contudo, notamos que para caracterizar um grupo colaborativo, nos moldes destacados pela literatura mencionada, no programa de iniciação à docência, por exemplo, temos a interação entre os sujeitos da Universidade (coordenadores e licenciandos) e sujeitos da escola pública (professores supervisores) em prol de objetivos comuns: seu desenvolvimento profissional ao lecionarem e a aprendizagem matemática dos alunos.

\section{Do Oiapoque ao Chuí: levantamento de teses e dissertações de pesquisas sobre o PIBID}

No ano de 2010, o Governo Federal, estabeleceu pela portaria normativa da Coordenação de Aperfeiçoamento de Pessoal de Nível Superior (CAPES) n 16, em 23 de dezembro 2009, a implementação do Programa Institucional de Bolsas de Iniciação à Docência (PIBID) com o intuito de suprir as lacunas formativas em cursos de licenciatura do país.

De acordo com Silveira (2015, p. 5), o PIBID "[...] contribui para que as licenciaturas possam aproximar-se mais da escola, promover a interação ente os formadores e melhorar as

manhã, das $9 \mathrm{~h}$ às $12 \mathrm{~h}$, para estudar, compartilhar, discutir, investigar e escrever sobre a prática pedagógica em matemática nas escolas em um ambiente de trabalho colaborativo que congrega professores de matemática do ensino fundamental e médio e docentes da área de educação matemática da FE/Unicamp. 
concepções dos estudantes dos cursos de formação inicial sobre a escola e suas práticas". O objetivo do programa consiste em promover aproximações entre as instituições formadoras e as escolas de Educação Básica e, dessa forma, inserir os acadêmicos no campo de sua futura atuação. O PIBID é financiado pela CAPES e suas ações são previstas pelo Ministério da Educação (MEC).

Dada conceituação do programa, com a intenção de mapear o que dizem estudos que têm a "iniciação à docência" como objeto de pesquisa (mestrado e/ou doutorado) no campo da Educação Matemática, realizamos um levantamento junto ao Catálogo de Teses e Dissertações defendidas em Programas de Pós-Graduação em Educação de Universidades $^{3}$ federais e estaduais das cinco regiões do país (Norte, Nordeste, Centro-Oeste, Sudeste e Sul) no período de 2010 a 2018.

A busca ocorreu com base no critério de eleger duas instituições por região, sendo uma federal e a outra estadual, uma vez que não é característica desta pesquisa realizar um estado da arte de modo que este se constitua a análise central dos dados, mas sim, para que nos dê um panorama situado de como o programa se torna objeto de reflexão em investigação "de" e "sobre" a formação de professores. Destarte, podemos observar a da produção científica que envolve o descritor "PIBID" na Tabela 1.

Tabela 1: Mapeamento de teses e dissertações defendidas nas 5 regiões do Brasil (2010-2018).

\begin{tabular}{|c|c|c|c|c|c|c|c|c|c|c|c|c|}
\hline \multirow{5}{*}{ REGIÕES } & \multirow{5}{*}{ IES's } & \multicolumn{9}{|c|}{ ANO DA PRODUÇÃO } & \multirow{5}{*}{$\begin{array}{l}\text { Subtotal } \\
\text { por IES }\end{array}$} & \multirow{5}{*}{$\begin{array}{l}\text { Total por } \\
\text { Regiốes }\end{array}$} \\
\hline & & 2 & 2 & 2 & 2 & 2 & 2 & 2 & 2 & 2 & & \\
\hline & & 0 & 0 & 0 & 0 & O & 0 & O & 0 & 0 & & \\
\hline & & 1 & 1 & 1 & 1 & 1 & 1 & 1 & 1 & 1 & & \\
\hline & & $\mathbf{0}$ & 1 & 2 & 3 & 4 & 5 & 6 & 7 & 8 & & \\
\hline \multirow{2}{*}{$\begin{array}{l}\text { Centro- } \\
\text { Oeste }\end{array}$} & UFGD & - & - & - & - & - & - & - & 1 & - & 1 & \multirow[t]{2}{*}{2} \\
\hline & UEMS & - & - & - & - & - & 1 & - & - & - & 1 & \\
\hline \multirow[t]{2}{*}{ Nordeste } & UFRN & - & - & - & - & - & 1 & 1 & 2 & - & 4 & \multirow[t]{2}{*}{8} \\
\hline & UNEB & - & - & - & - & 1 & - & 1 & 1 & 1 & 4 & \\
\hline \multirow[t]{2}{*}{ Norte } & UFT & - & - & 1 & 2 & - & - & - & & 1 & 4 & \multirow[t]{2}{*}{5} \\
\hline & UEPA & - & - & - & - & - & - & 1 & - & - & 1 & \\
\hline \multirow[t]{2}{*}{ Sudeste } & UFSCar & - & - & - & 1 & 2 & 2 & 1 & - & - & 6 & \multirow[t]{2}{*}{7} \\
\hline & UNESP & - & - & - & - & - & - & 1 & - & - & 1 & \\
\hline \multirow[t]{2}{*}{ Sul } & UFRGS & - & - & - & 1 & 1 & 4 & - & 1 & - & 7 & \multirow[t]{2}{*}{7} \\
\hline & UEL & - & - & - & - & - & - & - & - & - & - & \\
\hline \multicolumn{8}{|c|}{ TOTAL GERAL DE TRABALHOS } & & & & \multicolumn{2}{|c|}{29} \\
\hline
\end{tabular}

Fonte: Os autores (2018)

\footnotetext{
${ }^{3}$ Adotamos o critério de eleger uma instituição estadual e uma federal.
} 
Dentre os 29 (vinte e nove) trabalhos localizados, 24 (vinte e quatro) eram sobre o PIBID de maneira geral em experiências nos mais diversos cursos de licenciatura como, por exemplo, Química, Educação Física, Música, Arte, dentre outros e 5 (cinco) tratavam-se, especificamente, da Educação Matemática e, portanto, serão analisados a seguir.

Diante das especificidades do mapeamento, delimitamos através do número de pesquisas encontramos a necessidade de categorizar e apresentar as que se referiam ao programa em cursos de Pedagogia e Matemática. Desse modo, realizou-se a leitura prévia dos resumos das teses e dissertações e, nesta ação, verificou-se as produções que aqui serão expostas.

Na região Nordeste, na Universidade Federal do Rio Grande do Norte (UFRN) encontramos 1 (uma) dissertação (CRUZ, 2017) e 1 (uma) tese (MENDONÇA, 2016).

Cruz (2017), cujo trabalho intitula-se "O PIBID de Matemática como espaço de formação inicial e continuada na UFRN/Natal", teve como objetivo contribuir para a formação inicial e continuada de professores de Matemática a partir das ações desenvolvidas no programa da instituição em questão.

Para resgatar essas contribuições, o caminho trilhado foi primeiramente a interpretação de documentos referente ao PIBID da licenciatura em Matemática e, em seguida, a realização de entrevistas semiestruturadas com depoimentos de pessoas diretamente envolvidas na proposta, com o intuito de perceber como aquele contexto os influenciou na formação profissional.

Por fim, o pesquisador percebeu direcionamentos que apontam à formação profissional dos estudantes, visando a minimizar o impacto no início da carreira docente com a aproximação entre a escola e a Universidade. O PIBID de Matemática da UFRN oferece o auxílio na compreensão do que é ser professor, uma vez que muitos profissionais só conhecem a "realidade da escola" após a fase inicial da formação quando não se pode contar mais com suporte que ficaram da Instituição de Ensino Superior.

Durante a investigação ocorreram momentos de pensar em estratégias, pesquisar alternativas, refletir e auxiliar nas expetativas dos participantes do programa e dos alunos da turma em que o PIBID atuava, os alunos traziam falas, questionamentos ou exemplificações que, de certo modo, ajudaram na reflexão do verdadeiro aprendizado de ser professor. Desse modo, foi perceptível a amplitude e o esforço das ações do subprojeto da UFRN-Natal em prol da melhor qualidade na formação dos futuros professores, assim como na formação continuada.

Em suma, com a conclusão da dissertação, ao que os dados indicaram, foi evidente também que as ações desenvolvidas envolvem todo o grupo integrante do programa, fazendo 
com que as práticas sejam favoráveis a uma formação inicial voltada ao conhecimento da dinâmica de atuação na escola e uma formação continuada que implica constante investigação e pesquisa sobre a própria prática.

O segundo trabalho foi uma tese de Mendonça (2016) intitulada "Representação social sobre o ensino de Matemática de licenciandos vinculados ao PIBID: dinâmica de formação". No início da escrita deste texto, foi realizado um breve histórico da jornada de aprendizagem mostrando o interesse e conquista do movimento do ser professor e pesquisador, juntamente com o tema abordado. O objetivo era identificar as representações sociais dos licenciandos, bolsistas do Programa Institucional de Bolsas de iniciação à Docência, sobre o ensino de Matemática e enfatizar os benefícios do contato com os alunos da rede pública para sua formação.

A pesquisa foi realizada com licenciandos de Matemática atuantes no Ensino Médio de três escolas estaduais. Com vista a atingir o objeto do trabalho, a tese foi construída por considerar a prática docente um contexto fundamental para se efetivar a busca de informações e reflexões que envolvam aspectos teóricos e práticos da formação dos professores. Adotou-se uma metodologia qualitativa, buscando reunir algumas formas que os educadores encontram para praticar um modelo de Educação Matemática com um grupo de acadêmicos. Por meio das necessidades identificadas nas discussões, foram elaborados princípios norteadores para uma prática educativa pautada na aprendizagem significativa e essa elaboração foi realizada com um conjunto de professores em exercício (os supervisores do programa). Com base na coleta de dados, da preparação e realização de projetos, entrevistas e análise documental, a autora sinaliza, em suas análises, os caminhos para que a intervenção do PIBID fosse realizada.

Ao final da intervenção realizada pelo grupo e com a entrevista semiestruturada, Mendonça (2016) se deparou com depoimentos que revelaram que a maioria não tinha intenção de ser professor, principalmente de Matemática, e que o ingresso no curso derivou-se da proximidade com a moradia, por ser o curso superior mais próximo de suas residências. No decorrer do trabalho os futuros professores tecem críticas ao processo de formação dos professores mais antigos já atuantes nas escolas parceiras, justamente por encontrarem resistências de colocar em ação a teoria e tendências em Educação Matemática que estudavam na licenciatura.

Em meio a tantas reflexões e constatações, a autora concluiu que o processo de vivência, reflexão e reconstrução das práticas pedagógicas desencadeadas na formação inicial, por intermédio do PIBID, contribui à promoção de um ensino inovador, significativo e democrático aos discentes, buscando a superação dos desafios experienciados. 
Na região Sudeste, localizamos 7 (sete) trabalhos distribuídos entre a Universidade Federal de São Carlos (UFSCar) e a Universidade Estadual Paulista (UNESP). Na UFSCar foram encontrados 7 (sete) trabalhos com a temática geral sobre o programa, os quais discutiram suas contribuições em diferentes licenciaturas, dentre estes, encontramos a maior concentração de trabalhos na área do PIBID-MATEMÁTICA. Nesta instituição, foram encontradas 4 (quatro) dissertações e 2 (duas) teses, sendo 2 (duas) destas dissertações voltadas para a nossa pesquisa.

A primeira pesquisa foi 1 (uma) dissertação defendida no ano de 2013 por Roger Eduardo Silva Santos intitulada "Formação de professores que ensinam Matemática anos iniciais: contribuições do Programa Institucional de Bolsas de Iniciação à Docência (PIBID) na UFSCar". Este estudo teve como objetivo identificar e analisar as contribuições do processo de formação docente, em relação à Matemática, revelados em narrativas orais e nas produções escritas de licenciandos do curso de Pedagogia que participam de programa. A investigação buscou delinear e analisar os principais sentimentos, percepções e reflexões vivenciadas pelos futuros professores (SANTOS, 2013).

Em termos metodológicos, a abordagem qualitativa foi a base central para o tratamento dos dados em que fora utilizado o PIBID/UFSCar como cenário da investigação. Diante das delimitações estabelecidas, foi feito recortes em portfólios e diários de campo produzidos pelos quatro bolsistas do programa, que trabalham especificamente com o projeto de jogos matemáticos.

A coleta das informações foi constituída de documentos oficiais do PIBID, portfólios, diários e entrevistas semiestruturadas realizadas com quatro licenciandos, sendo eles bolsistas de iniciação à docência, uma docente coordenadora do subprojeto da licenciatura em Pedagogia e duas professoras bolsistas do Ensino Fundamental. Os elementos utilizados para o processo de elaboração da dissertação foram separados em dois eixos: "analisando os sentimentos vivenciados no processo de iniciação à docência" e o "da emergência de uma Matemática escolar durante o processo formativo".

Como um dos resultados centrais, a pesquisa evidenciou que além dos principais sentimentos apontados como, por exemplo, as descobertas, sobrevivência e choque de realidade, observou-se no processo vivenciado na formação inicial sentimentos de pertença, satisfação, parceria e de acolhimento (SANTOS, 2013).

$\mathrm{Na}$ análise de dados, foram evidenciadas as contribuições do programa para que ampliassem as vivências, reflexões no âmbito da complexidade de inserção no contexto escolar na relação entre a teoria e a prática pedagógica. $\mathrm{O}$ autor ressalta ainda que com a presença do 
jogo nas aulas de Matemática, os licenciandos puderam auxiliar no problema da indisciplina, que foi amenizado de acordo com o depoimento dos bolsistas, os alunos se viam em situação desafiadora, a qual exigia deles maior concentração nas atividades.

Por fim, percebeu-se em relação à Matemática dois olhares no processo de iniciação à docência, sendo que estes estavam sempre voltados para as próprias aprendizagens, porém, sempre pensando na aprendizagem dos alunos da escola e não, necessariamente, na dos futuros professores, que é o foco do PIBID. Dessa forma, participar desta experiência durante a formação de professores proporcionou um espaço de busca da articulação entre teoria e prática, no qual surgiram percepções e reflexões destes dois olhares: o aprender dos alunos e o aprender ofícios da profissão.

A segunda dissertação foi defendida no ano de 2014 por Danielli Ferreira Silva que apresentou a pesquisa intitulada "Processo de iniciação à docência de professores de Matemática: olhares de egressos do PIBID/UFSCar". Teve como objetivo compreender o processo de iniciação à docência dos egressos do Programa Institucional de bolsas de Iniciação à Docência (PIBID) com o intuito de identificar as contribuições e limites desse processo formativo sob o olhar dos bolsistas egressos.

A questão que norteou a pesquisa foi: "Quais as principais percepções dos egressos do PIBID/UFSCar de matemática em processo de iniciação à docência sobre dificuldades e aprendizagens da carreira docente?" (SILVA, 2014, p. 11). Para alcançar o objetivo proposto, a autora optou por três etapas: a) primeiramente foi realizado um mapeamento dos bolsistas que participaram do programa e para eles foram encaminhados questionários; b) foi realizado um segundo mapeamento só que agora com os cinco egressos que mais se destacaram no questionário anterior, com o intuito de traçar um perfil sobre a análise das escritas reflexivas desses egressos; e c) entrevistas com quatro sujeitos colaboradores a fim de compreender as percepções sobre o processo de formação de entrada na profissão e perspectivas futuras.

A pesquisadora teve como ponto central do trabalho o resultado de que o PIBID se apresenta como um programa de formação que busca proporcionar esse momento de articulação entre teoria e prática aos licenciandos, buscando superar as dicotomias entre a Matemática escolar e a Matemática acadêmica da formação inicial que reflete diretamente na prática pedagógica e na transposição didática na escola.

Por fim, Silva (2014) concluiu que existem limites no processo de iniciação à docência a serem superados quanto ao estabelecimento de parceiros entre as diversas áreas do conhecimento na promoção da interdisciplinaridade. Fazendo-se necessário que os espaços 
envolvidos estejam comprometidos nessas ações e repensem, a todo o momento, os seus papéis na sociedade atual.

O último trabalho encontrado nesta mesma região vincula-se à Universidade Estadual Paulista "Júlio de Mesquita Filho" - UNESP - a qual teve 1 (uma) tese. A investigação em questão foi defendida no ano de 2016 por Márcio Urel Rodrigues, intitulada "Potencialidades do PIBID como espaço formativo para professores de Matemática no Brasil". O objetivo era perceber como as ações deste ambiente tornam-se, com as vivências experienciadas por seus bolsistas, um terceiro espaço formativo que contribui para fortalecer um modelo que articula teoria e prática na licenciatura em Matemática.

Para alcançar o objetivo proposto foi adotada a pesquisa qualitativa, a qual se valeu de dos contextos práticos: questionário com supervisores e licenciandos em Matemática, entrevista com coordenadores instituições ou Universidades.

A organização da análise de dados demonstra a existência das seguintes categorias emergentes do estudo: a) dimensões do grupo PIBID/Matemática; b) parcerias na formação de professores; e c) possibilidades do PIBID como política de formação de professores e formação profissionalização docente (RODRIGUES, 2016). Face aos resultados finais, o estudo mostrou que o PIBID constituiu-se como "terceiro espaço" para formação de professores de Matemática no Brasil, pois proporcionou aproximação das Universidades com escolas e a articulação entre teoria e a prática. Para finalizar, compreendeu-se que o PIBID tem contribuído para redimensionar processos formativos de professores de Matemática ao oportunizar uma discussão que contribui com a formação de educadores matemáticos em nosso país.

Em síntese, com este mapeamento de teses e dissertações, percebe-se um movimento da constituição de focos/tendências de investigações "de" e "sobre" o PIBID que parecem caminhar para a problematização dos seguintes pontos deste programa: a) Foco 1- Formação inicial; b) Foco 2- Olhar dos licenciandos e egressos; e c) Foco 3- PIBID como um terceiro espaço de formação.

No Foco 1, observamos que 2 (duas) pesquisas (SANTOS, 2013; CRUZ 2017) investigaram a formação inicial de professores para o ensino de Matemática. Ambas procuraram analisar contribuições do processo de formação docente em relação ao ensino dos conteúdos matemáticos diante dos sentimentos, percepções e reflexões vivenciadas pelos futuros professores. Para os autores, a participação dos futuros professores no programa pode contribuir para uma formação mais ampla, pois os sujeitos que do PIBID participaram, nestas pesquisas, puderam ter contato com autores e conteúdos que na graduação não tiveram, passaram por situações desafiadoras, mas por estarem inseridos no programa puderam refletir 
e encarar as situações visando minimizar o impacto do início da docência ainda no curso de licenciatura, o que fortalece a construção da identidade com a carreira.

No Foco 2, os estudos desenvolvidos por Mendonça (2016) e Cruz (2017) destacaram relações adquiridas por licenciandos e egressos diante do ensino de Matemática. As duas pesquisas se realizam na perspectiva de relatar como funcionou o contato e os benefícios aos quais os licenciandos puderam obter ao participarem de um programa de iniciação à docência. Analisaram que houve desafios e barreiras a serem enfrentadas, mas que foram superadas diante da forma a qual o programa foi se consolidando nos espaços/tempos em que as investigações ocorreram. Os licenciandos e egressos tiveram contato a todo o momento com a teoria e prática ao mesmo tempo, proporcionando caminhos diversos para enfrentarem os percalços do cotidiano escolar.

Por fim, o Foco 3, enquadra-se a pesquisa de Rodrigues (2016) que chamou atenção quando trouxe um novo enfoque para o PIBID, lhe conferindo a possibilidade de este ser um terceiro espaço de formação docente. Os resultados demostraram que o programa contribui, de forma significativa, para um avanço no ensino da Matemática, que através dessa política os licenciandos que têm o privilégio de participarem acabam por desenvolver um conhecimento didático para o ensino, bem como que este é uma importante via de construção da identidade com a carreira.

Observamos, em todos os estudos realizados, acerca dos focos apresentados que os integrantes que participam do programa adquirem um contato com autores que enriquecem seu campo de atuação e que os mesmos, por terem essa oportunidade, remetem uma capacidade maior de reflexão sobre suas ações e isso se estende dos acadêmicos aos professores coordenadores e supervisores, bem como obtêm contato direto com a Matemática, pensando em maneiras de diversas de torná-la mais acessível aos alunos.

\section{Delineamento metodológico}

No caminho trilhado para o desenvolvimento desta pesquisa, nos propusemos a compreender como a prática colaborativa de estudos, reflexões e intervenções de um grupo de iniciação à docência constitui-se como espaço de aprendizagem compartilhada "de" e "sobre" a docência em Matemática, especificamente em um curso de Pedagogia.

Para este fim, a abordagem metodológica adotada refere-se à pesquisa qualitativa em educação, de caráter descrito-analítico. De acordo com Bogdan e Biklen (1994), os dados qualitativos são caracterizados pela riqueza de detalhes descritivos, pois o tratamento estatístico 
se torna complexo. A pesquisa qualitativa não se dá através de variáveis, pois buscam "[...] investigar os fenômenos em toda a sua complexidade e em contexto natural, [...] Privilegiam, essencialmente, a compreensão dos comportamentos a partir da perspectiva dos sujeitos da investigação" (BOGDAN; BIKLEN, 1994, p. 16).

Nesta direção, os dados foram coletados na perspectiva de atingir os seguintes objetivos específicos e indicadores de análise de dados:

Quadro 1: Relação entre os objetivos específicos e indicadores de análise de dados.

\begin{tabular}{|c|c|}
\hline OBJETIVOS & INDICADORES \\
\hline $\begin{array}{l}\text { 1. Identificar aspectos da aprendizagem da } \\
\text { docência decorrentes das atividades do } \\
\text { PIBID; }\end{array}$ & $\begin{array}{l}\text { - Problemas da formação inicial; } \\
\text { - Práticas de gerenciamento das ações do } \\
\text { grupo; } \\
\text { - Sentimentos dos/das bolsistas a partir de } \\
\text { sua inserção no ambiente escolar. }\end{array}$ \\
\hline $\begin{array}{l}\text { 2. Caracterizar em que sentido as } \\
\text { intervenções e trabalhos realizados no } \\
\text { programa contribuem para a formação } \\
\text { inicial na perspectiva da colaboração; }\end{array}$ & $\begin{array}{l}\text { - Características do trabalho colaborativo; } \\
\text { - } \quad \text { doutonomia das } \\
\text { acadêmicos/acadêmicas; } \\
\text { - Capacidade de explicitar o referencial } \\
\text { teórico de atuação do grupo; } \\
\text { - Justificativas para ações de intervenção; } \\
\text { - Prática de planejamento coletivo. }\end{array}$ \\
\hline $\begin{array}{l}\text { 3. Analisar a percepção das acadêmicas } \\
\text { bolsistas acerca do repertório didático- } \\
\text { pedagógico e da formação para o ensino } \\
\text { de Matemática oportunizadas no grupo } \\
\text { PIBID }\end{array}$ & $\begin{array}{l}\text { Entrevistar duas acadêmicas que } \\
\text { participam e duas que já estão formadas, } \\
\text { mas que já passaram pelo programa. } \\
\text { Realizar análise de dados obtidos para } \\
\text { refletir sobre a pesquisa construída. }\end{array}$ \\
\hline
\end{tabular}

Fonte: Os autores (2018).

Para atingir os objetivos delimitados acima, o trabalho de campo envolveu as seguintes fases:

a) Constituição do referencial teórico: em que foi realizada uma pesquisa bibliográfica para que pudéssemos nos familiarizar com os autores que abordam, em seus focos de investigação;

b) Levantamento de teses e dissertações: de modo que buscamos reunir trabalhos defendidos em Programas de Pós-Graduação em Educação de Universidades Estaduais e Federais das cinco regiões do país (Norte; Nordeste; Centro-Oeste; Sudeste e Sul);

c) Mapeamento das colaboradoras do estudo e roteiro de entrevista: após uma fundamentação teórica, passamos ao processo de identificação de bolsistas e exbolsistas que poderiam contribuir concedendo uma entrevista semiestruturada. Assim, localizamos um total de 13 (treze) egressas do PIBID, entre os anos de 2014 e 2017, e 8 bolsistas em atividade no ano de 2018. O critério para a escolha 
dos participantes do estudo decorreu da necessidade que tínhamos de tentar, ao menos em tese, avaliar a contribuição das ações colaborativas para a constituição de um referencial teórico de atuação com o ensino de Matemática. Face à isso, optamos por trabalhar com uma ex-pibidiana (egressa de 2016, que esteve no PIBID desde sua implementação) e uma atual bolsista (participante do grupo desde 2015), haja vista o critério exposto na fase da entrevista a seguir.

d) Entrevista semiestruturada: tendo em vista todo o estudo teórico realizado, convidamos duas colaboradoras (uma pibidiana e uma ex-pibidiana) para participação voluntária no estudo por meio de uma entrevista semiestruturada que, de acordo com por Manzini (2012), é um procedimento amplo que, por vezes, encontra-se em pesquisas científicas e são encaradas pelos autores como método, instrumento e/ou técnica direta de produção de dados. O critério para escolha das colaboradoras foi o de tempo/permanência no grupo, sendo assim, uma pessoa que tivesse adentrado neste espaço formativo desde o começo de sua graduação (a pibidiana) e alguém que já teve tal experiência e hoje atua como professora (expibidiana);

e) Análise de conteúdo: momento este em que, com base nos dados coletados, direcionamos os olhares críticos para a descoberta de núcleo e sentidos encontrados em comunicações (enunciados dos sujeitos). Bardin (2009) destaca três etapas para uma análise de qualidade: a) pré-análise; b) exploração do material; c) tratamento dos resultados. Com base nestas etapas, a autora vem nos mostrar um novo propósito para ultrapassarmos, sendo este o senso comum e alcançarmos a maior exatidão científica necessária.

Dadas às etapas deste estudo, tentamos, com base nos resultados, categorizar a descrição da coleta de dados para que esta possibilite ao leitor compreender aspectos do subprojeto do PIBID do curso de Pedagogia da UFMS, as vozes das futuras professoras e as formas de organização do trabalho pedagógico com a Matemática.

\subsection{Caracterização das bolsistas participantes da pesquisa}

A pibidiana é a licenciada em Letras por uma Instituição de Ensino Superior particular da região e, atualmente, cursa o último ano de Pedagogia, quando entrevistada estava no sétimo semestre. Integrava a equipe de acadêmicos do programa desde seu ingresso na Universidade, 
no ano de 2015, permanecendo no grupo por quatro anos consecutivos, tornando-se uma das mais antigas participantes e vivenciou muitas experiências no PIBID.

A segunda entrevistada, a ex-pibidiana, formada no ano de 2017 em Pedagogia, fez parte do programa no período de 2014 a 2017, atuando por três anos como bolsista e, quando concedeu a entrevista, era professora particular de uma criança que tem Síndrome de West ${ }^{4}$. A criança não frequenta a escola regular tendo em vista sua especificidade, mas os familiares fizeram questão que ela tivesse um acompanhamento escolar para que fosse educada em casa.

\section{O PIBID de Pedagogia do Campus Naviraí: síntese da caracterização do grupo}

O Programa Institucional de Bolsas de Iniciação à Docência - PIBID - foi implementado no Campus Naviraí em fevereiro do ano de 2014 a partir do Edital 61/2013 da Coordenação de Aperfeiçoamento de Pessoal de Nível Superior - CAPES. A dinâmica de gerenciamento das ações do grupo se desenvolve, desde sua fundação, com base em planejamentos quadrimestrais, momento em que são elegidos temas centrais de discussões com os acadêmico-bolsistas.

As referidas discussões ocorreram diante da necessidade formativa dos integrantes no que se refere ao processo de inteirar-se sobre alfabetização/letramento e do ensino de Matemática, a partir de diferentes abordagens didático-pedagógicas como, por exemplo, jogos, brincadeiras, materiais manipuláveis, entre outros. Concomitantemente as reuniões de formação de equipe, ocorrem também observações e coparticipações em uma sala de aula do ciclo da alfabetização. Paralelamente a essas atividades, realizam-se reuniões de na Universidade periodicamente para discussão dos textos relacionados com a prática vivenciada, posteriormente, são planejados, de forma coletiva, sequências didáticas e projetos de ensino para o trabalho com as crianças.

Em uma breve retrospectiva, no ano de 2014 e 2015, o PIBID Pedagogia atuou no $2^{\circ}$ ano do Ensino Fundamental em uma escola da periferia da cidade, constituída por 31 alunos. Em 2016, ainda na mesma instituição, passou a realizar suas intervenções no $3^{\circ}$ ano. Em 2017, ocorreu uma mudança tanto de escola quanto do grupo de bolsistas, o que gerou a necessidade de rever o campo de atuação e seu gerenciamento. Assim, quando do momento da escrita deste

4 O diagnóstico da Epilepsia é classicamente baseado na presença de crises epilépticas. Estas apresentam-se de forma bastante variada, embora o público normalmente acredite na existência somente de crises típicas, como a crise tônico-clônica generalizada, conhecida popularmente como "ataque epiléptico" (Disponível em: https://www.neurologica.com.br/blog/sindrome-de-west-sintomas-da-epilepsia-e-diagnostico-precoce-embebes/.) 
texto, o programa de iniciação à docência realizava propostas de intervenções em uma turma de $1^{\circ}$ ano do Ensino Fundamental em uma escola da rede municipal local.

O referencial teórico constituído para as abordagens conceituais com a Educação Matemática nos anos iniciais refere-se a leituras de autores como: Smole, Diniz e Cândido (2000), Santos e Mendonça (2005), Soares (2005), Ferreiro (2012), Damiani (2008), Calil, Junqueira e Silva (2015), dentre outros.

As ações deste subprojeto concebem o processo de ensino e aprendizagem matemática como sendo de suma importância para a vida em sociedade e as atividades realizadas pautamse numa perspectiva lúdico-exploratória. O grupo em questão vem atuando com o foco de formar um professor que encare ser necessário constituir novas maneiras para que seu aluno possa assimilar os conteúdos matemáticos de forma prazerosa para que isso não venha se tornar no futuro um empasse em sua vida.

\section{As vozes das futuras professoras: o que aprenderam "de" e "sobre" Educação Matemática nos anos inicias}

Autores como Diniz-Pereira (1999) e Vicente (2016) consideram que os cursos de formação estão pautados em um modelo técnico, em que apresenta-se primeiro a teoria, momento em que os acadêmicos veem as disciplinas científicas relacionadas normalmente a área específica de cada licenciatura e, no segundo momento, as disciplinas pedagógicas e os estágios. Nessa direção, almejamos saber como ocorreu o primeiro contato com a Matemática no decorrer do curso de Pedagogia:

[...] Tive contato com a Matemática nas disciplinas de Matemática no quarto e quinto semestres do curso, porém, já fazia parte do PIBID, já fazia intervenção tanto na área da Matemática quanto na área da alfabetização (Egressa do PIBID).

[...] Meu primeiro contato com a Matemática foi no Programa Institucional de Bolsas de Iniciação à Docência, mas no curso de Pedagogia ocorreu nas disciplinas de Matemática que estão no quarto e quinto semestre, porém, ocorrem de maneira bem breve e superficial, precisando de um aprofundamento (Pibidiana).

Reportando-nos para o modelo formativo de professores, tal como anuncia DinizPereira (1999), as declarações das entrevistadas reforçam que na licenciatura parece ocorrer de fato a dissociação entre a unidade teórica e a unidade prática de ensino, pois em ambos os casos percebemos que o contato com a Matemática somente ocorreu nos primeiros momentos do curso porque o programa de iniciação à docência possibilitou-as experiências com a Educação 
Básica, uma vez que a disciplina destinada a essa área do conhecimento está alocada na metade de suas formações.

Face aos depoimentos, fica evidente que o contato com a Matemática ocorreu antes mesmo da disciplina colocada na grade curricular. Partindo deste princípio, questionamos quais momentos consideraram primordiais para a ampliação dos conhecimentos, se isso ocorreu nas disciplinas de metodologia ou teve algo além, a egressa do PIBID menciona: "estou aplicando os conhecimentos que adquiri tanto na Universidade quanto no PIBID, pois a Matemática tem que ser inserida na vida da criança desde cedo".

A pibidiana considera que os conhecimentos mais significativos vieram durante sua passagem pelo programa: "já tenho uma formação e quando entrei nesta graduação jamais imaginei que pudesse ter Matemática, e quando me deparei com ela, já estava familiarizada, pois já estava atuando com a Matemática no PIBID". Para Costa (2013), é muito frequente que os estudantes tenham uma resistência quando vão optar por uma graduação e muitos procuram as áreas de humanas por pensarem que dentro delas não terá a tão temida Matemática que é considerada uma "vilã", isso porque ela conquistou uma imagem, ao longo dos anos, negativa frente ao ideário social.

[...] uma imagem que não corresponde a sua função, fortemente difundida em todas as classes sociais, permeada de conotações cada vez mais negativas que lhe conferem títulos desastrosos. Ou seja, a Matemática tornou-se a "vilã" em diversos ambientes, seja ele escolar ou não [...] A Matemática é colocada como um saber destinado a alguns privilegiados que pela sua grande e indiscutível capacidade intelectual, se destacam em sociedade. Quando não é utilizada como forma de dominação por parte daqueles que percebem seu "poder" perante uma maioria marcada por influências negativas, frutos das crenças alimentadas ao longo dos anos (COSTA, 2013, p. 1-2).

Dando continuidade na entrevista, buscamos compreender, dadas as afirmações de que o PIBID foi a via primeira de contato com a disciplina, em quais aspectos ele proporciona aos seus bolsistas uma relação entre teoria e prática:

[...] o programa me proporcionou uma relação direta entre a teoria e a prática, pois os integrantes do grupo faziam reuniões de estudos teóricos e, concomitantemente, faziam observações para em seguida realizar a intervenção nas escolas (Pibidiana).

[...] o PIBID fez a relação entre a teoria e a prática, que é o que falta nos cursos de Pedagogia, essa questão de irmos para a escola, depois de muito tempo de ter visto a teoria, nos deixa desnorteado, pois quando estamos atuando não pensamos em qual teoria utilizar, pois já não as lembramos com tanta frequência (Egressa do PIBID). 
Diante das falas, parece-nos evidente que uma das grandes contribuições do PIBID à formação de professores reside na possibilidade de articulação entre o que se coloca nas teorias e o que acontece no cotidiano da profissão docente. Ilustram essa afirmativa o fato de que tanto a pibidiana quanto a egressa explicitarem que no contexto das atividades de gerenciamento do grupo, ocorriam/ocorrem ações de estudos teóricos coletivos, intervenções na escola parceira em um processo de retroalimentação de fusão teoria-prática, haja vista que participar deste programa desde o início da licenciatura parece possibilitar uma visão mais situada de que não existe prática sem teoria e nem teoria sem prática.

Acreditamos que uma perspectiva formativa que se quer contribuir com a identidade docente e com a compreensão da dinâmica e cultura escolar, necessariamente, precisará ter a prática pedagógica como ponto de partida e o ponto de chegada. Perrenoud (1993) coloca que o problema mais grave que as licenciaturas enfrentam é a falta de articulação entre a teoria e a prática, ficando complicada a aproximação do futuro professor de seu ambiente de atuação.

Especificamente em relação à Educação Matemática, inquirimos as colaboradoras sobre suas percepções acerca de como se veem quando pensam o ensino da disciplina em uma perspectiva avaliativa de seu processo formativo:

[...] as experiências que o grupo me proporcionou me deram confiança para enfrentar o que viesse pela frente, tive um olhar diferenciado para com os meus estágios e só tive essa percepção por já ter passado por isso antes (Pibidiana).

[...] vivenciei a teoria e a prática juntos durante minha passagem pelo programa, foi um momento crucial para minha formação, pois a partir de minha passagem adquiri confiança e determinação para continuar, tentar e me superar a cada dia mais (Egressa do PIBID).

As reflexões da pibidiana e da egressa corroboram dados de pesquisas anteriores realizadas neste mesmo programa, cujos resultados apontaram que estar imerso a um contexto de formação "de" e "sobre" o ensino de Matemática resulta em uma autoconfiança, mudança de postura e maior segurança para tratar de conceitos específicos (CIRÍACO; SOARES, 2015). Contudo, atualmente, quando do momento da escrita deste texto, olhar para o potencial das práticas colaborativas decorrentes do trabalho e planejamento coletivo do PIBID nos leva hoje a pensar que os resultados apontados por Ciríaco e Soares (2015) só foram possíveis porque o programa de iniciação à docência constituiu-se no Campus de Naviraí como sendo um espaço colaborativo de formação inicial de professores.

Abaixo destacamos excertos que revelam a afirmativa acima: 
[...] A gente fazia reuniões periódicas toda semana para realizar estudos teóricos e, semanalmente, a gente fazia observações em dupla na escola parceira. Depois da observação, a gente planejava uma intervenção a partir do que a professora nos ajudava e nos indicava, a gente criava uma intervenção baseada nos estudos que aconteciam nas reuniões. Depois da intervenção, a gente pegava as observações, organizava em forma de relatos de experiência para apresentar em eventos em forma de artigos ou em forma de relatos de experiência mesmo, para apresentar o que era realizado pelo PIBID e apresentar os resultados positivos e negativos, porque não se tem só resultados positivos (Egressa do PIBID).

[...] Meu grupo é composto por oito acadêmicos, uma professora supervisora e um coordenador de área, fazemos reuniões periódicas todas as segundasfeiras e durante a semana fazemos as observações, cada dia é uma dupla, ao fim das observações é construída a intervenção coletivamente (Pibidiana).

Notamos em suas respostas um discurso similar, a organização do grupo era quase que a mesma, muito embora as duas tivessem integrado esse espaço em tempos distintos, o que revela uma característica importante de um grupo colaborativo: a da rotatividade. De acordo com Nacarato e Paiva (2013), os grupos colaborativos são formados por professores universitários, professores da Educação Básica e os acadêmicos, que juntos buscam respostas para sanar dificuldades cotidianas do trabalho nas escolas, bem como potencializam o seu desenvolvimento profissional em um aprofundamento teórico-metodológico em métodos e técnicas de ensino.

Para além do aspecto organizacional do grupo, que descrevemos na seção 5.1 deste artigo, buscamos compreender, a partir das vozes das entrevistadas, em que sentido os estudos e intervenções acerca da Educação Matemática as auxiliaram pensar formas de organização do trabalho pedagógico:

[...] Foi a partir da minha passagem pelo grupo e durante as reuniões que surgiu meu interesse em pesquisar meu trabalho de conclusão de curso, que foi voltada para área da Educação Matemática, percebi com o grupo que devemos trabalhar com Matemática, o quanto antes melhor para tirar esse medo que existe nas pessoas, que se isso for trabalhado desde o início na Educação Infantil se torna mais familiar durante sua vida escolar (Egressa do PIBID).

[...] Meu TCC está sendo construído com base na Educação Matemática e isso se deu por estar participando do grupo, se só tivesse contato com a Matemática pelas disciplinas, jamais passaria pela minha cabeça desenvolver algo na área da Matemática, hoje meu TCC fará uma intervenção para mostrar que a Matemática e os gêneros textuais podem e devem caminhar juntos (Pibidiana). 
Aparentemente, o fato de participarem de momentos em que o processo de ensino e aprendizagem matemática foi objeto de reflexão permanente, resultou em uma mudança de postura frente a disciplina, tanto que os temas de seus trabalhos de conclusão de curso (TCC's) recaíram neste campo. Ao que tudo indica, o PIBID apresenta-se como um dispositivo que auxilia na construção de uma identidade para além da docência, ao menos no caso analisado, pois as afirmativas de ambas recaem sobre o potencial deste espaço para formar professores pesquisadores na busca do saber Matemática.

[...] O PIBID, em meu ponto de vista, pode ser considerado um dos melhores grupos de iniciação à docência, gostaria que o grupo pudesse ser aberto para todos os acadêmicos, mas infelizmente o grupo é restrito [...] já o grupo ao qual eu faço parte é de muita interação, onde uns ajudam os outros, professores e acadêmicos trabalham em conjunto. Temos interesses pessoais?! Sim temos! Mas o grupo é unido! Um grupo sem articulação, companheirismo não pode ser considerado um grupo colaborativo [...] (Pibidiana).

[...] Como avaliação geral digo que o PIBID é um grupo maravilhoso, que traz para os acadêmicos uma autonomia incrível, os acadêmicos que têm a oportunidade de participar desse grupo saem da Universidade bem mais preparados para enfrentarem uma sala de aula [...] no grupo que participei tinha sim interesses particulares, mas isso não nos impedia de caminharmos juntos, uns contribuindo para a formação dos outros, coordenador de área, acadêmicos e professora supervisora, uns ajudam aos outros, alguns tinham dificuldade para escrever, outras para apresentar trabalhos, mas isso era superado quando estávamos todos de acordo e construindo juntos (Egressa do PIBID).

Construir junto, trabalhar coletivamente, auxiliar na superação de limitações e dificuldades, ter interesses pessoais e, ao mesmo tempo, grupais parece ser termos, sentenças, palavras e frases que alicerçam as bases sob as quais as ações de um trabalho colaborativo são consolidadas, o que demanda vivência, tempo e comprometimento de seus membros.

A construção contínua dos saberes não ocorre de forma isolada. Deve ser coletiva, com base em parcerias entre pessoas que estão em níveis de desenvolvimento profissional diferentes, fato esse observável no PIBID, pois temos acadêmicas, professores da Educação Básica e do Ensino Superior em prol de um mesmo fim: o ensino de Matemática (CIRÍACO; SAORES, 2015, p. 170-171).

Nesta perspectiva, conforme reconhecemos anteriormente, um grupo nasce cooperativo e torna-se colaborativo. Boavida e Ponte (2002), destacam algumas características desta vertente de trabalho que ficaram evidentes nos dizeres de nossas entrevistadas: a) confiança; b) diálogo; e c) negociação. 
[...] Entendo por trabalho colaborativo a forma de trabalho onde uns contribuem para a formação dos outros, considero meu grupo um grupo que trabalha de forma colaborativa, pois fazemos tudo em conformidade uns com os outros, ensaiamos para apresentar nossos trabalhos, uns palpitando na construção dos outros, mas para seu avanço e não para sua "diminuição" (Pibidiana).

[...] Creio que a compreensão sobre trabalho colaborativo ainda é pouca, mas o pouco que compreendo é que ainda tem que ser um trabalho feito para valorizar o trabalho do outro, se tivesse mais colaboração nos ambientes educacionais escolares e não escolares, nossa educação seria muito melhor, porque acontece muito na escola essa relação de poder, o mais experiente "manda" no menos experiente. Então, se não tivesse isso, se um professor mais experiente escutasse um professor com menos experiência valorizando o que ele tem para oferecer [...] (Egressa do PIBID).

Os termos "colaboração" e "grupo colaborativo" são comumente destacados durante a entrevista, pibidiana e egressa do programa, cada qual com a sua vivência, trazem para o diálogo o que compreendem destes conceitos, que para elas a base central deste tipo de trabalho resumese na valorização do trabalho seu e do outro de maneira respeitosa. Diante dos dados, podemos inferir que a "[...] construção compartilhada de conhecimentos favorece a autonomia dos participantes, possibilitando a eles além do que seria possível, se estivessem trabalhando individualmente" (BOLZAN, 2002, p. 63).

[...] Essa forma de trabalho contribuiu muito para minha passagem pela Universidade, conseguia relacionar a teoria que via na Universidade ao mesmo tempo em que estava inserida na escola e não era com estágio, mas sim, com a participação no PIBID, que me proporcionava esse intervir, escrever e refletir sobre o acontecido para apresentar esses trabalhos que foram escritos (Egressa do PIBID).

[...] Essa forma de trabalho me proporcionou um avanço no conhecimento, em minha outra graduação não tive essa oportunidade, hoje com minha participação no grupo tenho um vocabulário bem mais apurado, pois como nosso orientador sempre diz que só conseguiremos uma escrita de qualidade quando escrevermos e reescrevermos, quando lemos e relemos sempre para refletir e contribuir um pouco mais no que já está pronto e produzido (Pibidiana).

Ambas expressam que a prática colaborativa lhes trouxe uma visão de si diferente. Destacam que houve, desde sua inserção no programa, uma mudança significativa como pessoas e como profissionais, trabalhar colaborativamente possibilitou aprender com o outro e buscar soluções para problemas oriundos da prática escolar por meio da reflexão-ação-reflexão. Refletir contribuiu ainda para reorientá-las tanto no processo de reelaboração de seus saberes teóricos decorrentes das disciplinas do curso de Pedagogia quanto para a constituição de um repertório de saberes práticos da futura profissão, ao que o PIBID, enquanto espaço 
colaborativo de formação de professores que ensinam Matemática, revelou-se, neste estudo, como sendo um caso de êxito para os envolvidos.

\section{Considerações Finais}

Para o desenvolvimento deste estudo, tomamos como pressuposto a hipótese de que os professores têm uma grande dificuldade e barreiras enormes a serem ultrapassadas durante e após se licenciarem: relacionar teoria e prática. Diante disso, elaboramos objetivos aos quais queríamos investigar em um programa de iniciação à docência. O primeiro era identificar se houve aprendizado diante das intervenções realizadas pelo grupo PIBID, notamos que as aprendizagens que os acadêmicos que dele participam apontam uma postura diferenciada, demostram um domínio teórico-prático em múltiplas situações do cotidiano, observamos isso nas mais diversas complexidades, sendo algumas delas apresentadas em suas intervenções. Notamos a capacidade de manejar recursos que favorecem suas ações pedagógicas, diante do ensino da língua materna e do foco da investigação que se origina este texto: o ensino de Matemática.

Sobre o exercício da docência, é possível afirmar as entrevistadas passaram a conceber o processo de ensino e aprendizagem tanto dos alunos dos anos iniciais quanto delas próprias ao refletirem e avaliarem a importância e a eficácia do trabalho colaborativo para seu desenvolvimento profissional. Outro dado relevante é que, ter sido integrante do PIBID, despertou o interesse e o desejo pela pesquisa em Educação Matemática.

A experiência direta de coleta de dados a partir do mapeamento de teses de dissertações despertou o desejo de continuar investigando as razões para a pouca produção de trabalhos voltados para o "PIBID-Matemática", uma vez que esta lacuna na literatura, em termos pesquisas de mestrado e doutorado, nas cinco regiões brasileiras parece-nos, ao que os dados deste artigo indicaram, um problema ainda aberto.

\section{REFERÊNCIAS}

ALARCÃO, Isabel; CANHA, Bernardo. Supervisão e colaboração: uma relação para o desenvolvimento. Porto Editora, 2013.

BARDIN, Laurence. Análise de conteúdo. Lisboa: Edições v. 70, 2009.

BOAVIDA, Ana; PONTE, João Pedro da. Investigação colaborativa: potencialidades e problemas. In GTI (Org), Reflectir e investigar sobre a prática profissional. Lisboa: APM. p. 
43-55. Disponível em: https://repositorio.ul.pt/bitstream/10451/4069/1/02-BoavidaPonte\%20(GTI).pdf. Acesso em: 14 de abril de 2018.

BOGDAN, Robert; BIKLEN, Sari Knopp . Investigação qualitativa em educação: uma introdução à teoria e aos métodos. Porto: Porto Editora, 1994.

BOLZAN, Doris Pires Vargas. Formação de professores: compartilhando e reconstruindo conhecimentos. Porto Alegre: Mediação, 2002.

CIRÍACO, Klinger Teodoro; MORELATTI, Maria Raquel Miotto. Problemas experienciados por professores iniciantes em aulas de Matemática. Revista Eletrônica de Educação. v. 10, n. 3, p. 267-280, 2016. Disponível em:

http://www.reveduc.ufscar.br/index.php/reveduc/article/view/1719/526. Acesso em: 29 Jan. 2018.

CIRÍACO, Klinger Teodoro; SOARES, Rosiclér Gomes. Programa de iniciação à docência: o desenvolvimento profissional de estudantes de pedagogia em aulas de Matemática. Rev. Fac. Educ. (Univ. do Estado de M ato Grosso), vol. 23, ano 13, n.1, p. 151-173, jan./ jun. 2015. Disponível em: https://periodicos.unemat.br/index.php/ppgedu/article/view/1093/1187. Acesso em: 23 jun. 2018.

COSTA, Shirley Conceição Silva da. O professor que ensina Matemática nos anos iniciais: limites e possibilidades de um curso de formação inicial. In: Anais... XI Encontro Nacional de Educação Matemática. Educação Matemática: retrospectiva e perspectivas. Sociedade Brasileira de Educação Matemática/Regional Paraná. Guarapuava, PR, p. 1-14, 2013. Disponível em:

http://sbem.iuri0094.hospedagemdesites.ws/anais/XIENEM/pdf/3601_2027_ID.pdf. Acesso em: 13 de maio de 2018.

CRUZ, Klêffiton Soares da. O PIBID de Matemática como espaço de formação inicial e continuada na UFRN/Natal. 2017. 344f. Dissertação (Mestrado em Educação) Universidade Federal do Rio Grande do Norte, UFRN. 2017.

CURI, Edda. Formação de professores polivalentes: uma análise de conhecimentos para ensinar Matemática e de crenças e atitudes que interferem na constituição desses conhecimentos. 2004. 278f. Tese (Doutorado em Educação Matemática) - Pontifícia Universidade Católica de São Paulo. PUC/SP, São Paulo-SP. 2004.

DAMIANI, Magda Floriana. Entendendo o trabalho colaborativo em educação e revelando seus benefícios. Educar, Curitiba, n. 31, p. 213-230, 2008. Disponível em: http://www.scielo.br/pdf/er/n31/n31a13. Acesso em: 02 de março de 2018.

DINIZ-PEREIRA, Júlio Emílio. Formação de professores: pesquisas, representações e poder. $2^{\mathrm{a}}$ ed. Belo Horizonte: Autêntica, 2006.

FIORENTINI, Dario. Pesquisar práticas colaborativas ou pesquisar colaborativamente? In BORBA, Marcelo de C.; ARAUJO, Jussara de L. (Orgs.) Pesquisa qualitativa em Educação Matemática. Belo Horizonte: Autêntica, 2004. p. 47-76. 
FUSARI, José Cerchi. A educação do educador em serviço: o treinamento de professores em questão. 1988. 264f. Dissertação (Mestrado em Educação) - Pontifícia Universidade Católica de São Paulo, PUC/SP. São Paulo-SP. 1988.

FREIRE, Paulo. Pedagogia do oprimido. 17ª Ed. Rio de Janeiro: Paz e Terra, v. 3, 1987.

GHEDIN, Evandro; ALMEIDA, Maria Isabel de; LEITE, Yoshie Ussami Ferrari. Formação de professores: caminhos e descaminhos da prática. Brasília: Líber Livro Editora. $1^{\mathrm{a}}$ ed. 2008 .

GIL, Antônio Carlos. Como elaborar projetos de pesquisa. São Paulo: Editora Atlas. $4^{\mathrm{a}}$ ed. 2002.

GOMES, Maristela. Obstáculos epistemológicos, obstáculos didáticos e o conhecimento matemático nos cursos de formação de professores das séries iniciais do ensino fundamental. Revista Contrapontos, v. 2, n. 3, p. 363-376, 2008. Disponível em: https://siaiap32.univali.br/seer/index.php/rc/article/view/181/153. Acesso em: 30 de abril de 2018.

HARGREAVES, Andy. Os professores em tempos de mudança: o trabalho e a cultura dos professores na idade pós-moderna. Edição: Mc Graw-Hill. 1998.

MANZINI, Eduardo José. Uso da entrevista em dissertações e teses produzidas em um programa de pós-graduação em educação. Revista Percurso, p. 149-171, 2012.

Disponível em:

https://repositorio.unesp.br/bitstream/handle/11449/114753/ISSN21773300-2012-04-02149-171.pdf?sequence=1\&isAllowed=y. Acesso em: 12 de abril de 2018.

MENDONÇA, Silvia Regina Pereira de. Representação social sobre o ensino de Matemática de licenciandos vinculados ao PIBID: dinâmica de formação. 2016. $296 f$. Tese (Doutorado em Educação) - Universidade Federal do Rio Grande do Norte, UFRN. Natal. 2016.

NACARATO, Adair Mendes; PAIVA, Maria Auxiliadora Vilela. A formação do professor que ensina Matemática: perspectivas e pesquisa. Belo Horizonte: Autêntica. $3^{\text {a }}$ ed. 2013.

PERRENOUD, Philippe. Práticas pedagógicas, profissão docente e formação: perspectivas sociológicas. Lisboa. Dom Quixote, 1993.

PIMENTA, Selma Garrido. Formação de professores: saberes da docência e identidade do professor. Revista da Faculdade de Educação, v. 22, n. 2, p. 72-89, 1996. Disponível em: http://www.revistas.usp.br/rfe/article/view/33579/36317. Acesso em: 20 de fevereiro 2018.

RODRIGUES, Márcio Uriel. Potencialidades do PIBID como espaço formativo para professores de matemática no Brasil. 2016. 541f. Tese (Doutorado em Educação Matemática) - Universidade Estadual Paulista Júlio Mesquita Filho "Júlio de Mesquita Filho", UNESP, Rio Claro. 2016.

SARAIVA, Manuel; PONTE, João Pedro da. O trabalho colaborativo e o desenvolvimento profissional do professor de Matemática. Quadrante, p. 25-52, 2003. Disponível em: 
http://www.educ.fc.ul.pt/docentes/jponte/docs-pt/03-Saraiva-Ponte(Quadrante).pdf. Acesso em: 20 de fevereiro 2018.

SANTOS, Roger Eduardo Silva. Formação de professores que ensinam matemática nos anos iniciais: contribuições do Programa Institucional de Bolsas de Iniciação à Docência (PIBID) na UFSCar. 2013. 107f. Dissertação (Mestrado em Educação) - Universidade Federal de São Carlos - UFSCar. São Carlos. 2013.

SILVA, Danielli Ferreira. Processo de iniciação à docência de professores de Matemática: olhares de egressos do PIBID/UFSCar. 2014. 162f. Dissertação (Mestrado em Educação) Universidade Federal de São Carlos - UFSCar. São Carlos. 2014.

SILVEIRA, Helder Eterno da. Mas, afinal: O que é iniciação à docência? Atos de Pesquisa em Educação, v. 10, n. 2, p. 354-368, 2015. Disponível em:

https://proxy.furb.br/ojs/index.php/atosdepesquisa/article/view/4704/3046. Acesso em: $18 \mathrm{de}$ maio de 2018.

VICENTE, Marcelina Ferreira. Programa Institucional de Bolsas de Iniciação à Docência-PIBID-e a formação inicial de professores. 2016. 170f. Dissertação (Mestrado em Educação) - Faculdade de Ciências e Tecnologia da Universidade Estadual Paulista "Júlio de Mesquita Filho" - FCT/UNESP, Presidente Prudente-SP. 2016.

\section{SOBRE OS AUTORES:}

\section{Klinger Teodoro Ciríaco}

Ph.D. em Psicologia da Educação Matemática pela Faculdade de Ciências da Universidade Estadual Paulista "Júlio de Mesquita Filho" - FC/UNESP, Bauru-SP; Docente do Departamento de Teorias e Práticas Pedagógicas (DTPP) da Universidade Federal de São Carlos - UFSCar, São Carlos, Brasil; Programa de Pós-Graduação em Educação Matemática da Universidade Federal de Mato Grosso do Sul - UFMS, Campo Grande-MS; Líder do "MANCALA - Grupo de Estudos e Pesquisas em Educação Matemática, Cultura e Formação Docente" (CNPq/UFSCar). E-mail: klinger.ciriaco@ufscar.br

(iD https://orcid.org/0000-0003-1694-851X

\section{Yandra Karla dos Santos}

Licenciada em Pedagogia pela Universidade Federal de Mato Grosso do Sul - UFMS, Campus Naviraí, Brasil; Integrante do "MANCALA - Grupo de Estudos e Pesquisas em Educação Matemática, Cultura e Formação Docente" (CNPq/UFSCar). E-mail: yandra.familia24@gmail.com

iD https://orcid.org/0000-0002-7569-0451 